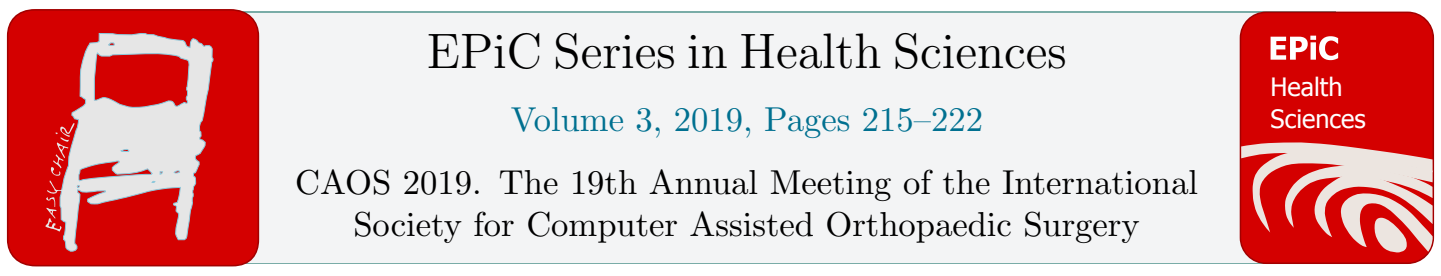

\title{
Gap deviation after cementation in computer assisted navigation TKA
}

Asst. Prof. AVM.Chumroonkiet Leelasestaporn, MD. Maj. Tomorn Tarnpichprasert, MD.

Adult Hip and Knee Reconstruction Unit, Department of Orthopaedic Surgery Bhumibol Adulyadej Hospital

\section{Introduction}

Total knee replacement is the most common operative treatment for osteoarthritis of knee ${ }^{[1]}$ with predictable results both in controlling the debilitating pain secondary to arthritis, and in returning compromised patients to a satisfactory functioning lifestyle ${ }^{[2]}$. The successful result is depended on many factors such as patient factors, prosthesis design and material, surgical technique, component position and alignment, soft tissue and gap balancing, and final mechanical axis ${ }^{[3,4]}$. Failure to implant proper position of prosthesis and unbalancing of soft tissue leading to premature loosening ${ }^{[5-8]}$ and early revision ${ }^{[9,10]}$.

Jawhar et al. ${ }^{[11]}$ showed that unbalanced gap total knee replacement patient had lower post-operative WOMAC score when comparing with balanced gap patient statistic significant difference.

In conventional technique TKA, gap and soft tissue balancing need surgeon experience and feeling to adjusted [12]. Unlike conventional, computer assisted navigation system has monitor display to show mechanical axis and gap in numerical and real time. That make operation more precise and accuracy in both bone preparation and soft tissue balancing [13-15]. Bathis et al. ${ }^{[16]}$ showed computer assisted TKA gives a better correction of alignment of the leg and orientation of the components compared with the conventional technique (mechanical axis within $+/-3$ degrees varus/valgus was $96 \%$ compared with $78 \%$ ). Pang et al. [17] showed significantly better limb alignment with fewer outliers (more than $3^{\circ}$ varus/valgus), smaller number of patients who has flexion contracture and better outcomes in Functional Score and Oxford Score in computer-assisted gap balancing technique when comparing with conventional measured resection technique.

Another step of operation that can influence successful outcome in TKA is cement technique. This technique included proper type of cement selection, proper bone surface preparation, adequate pressurization of cement, adequate removed 
extruded cement or cement debris, but the most important technique is equal load distribution and stabilized of prosthesis position during cement hardening because positioning of the components can considerable error in alignment, regardless of how accurately the resection planes are made ${ }^{[18,19]}$.

However, there has been limited number of studies about impact of cement correlation to gap and alignment in total knee replacement.

\section{Objective}

1. Primary objective: gap deviation after cementation in total knee replacement

2. Secondary objective: alignment deviation after cementation in total knee replacement

\section{Material and method}

This study is prospective analytic study. The inclusion criteria are all cases performed primary total knee replacement in Bhumibol Adulyadej hospital by a single surgeon with computer assisted navigation system. The patient who refused to enroll in this study, the patient who can not used computer assisted navigation system by any reason, the patient who have severe bone deformity or severe bone loss that need to used stem or metal augment, and revision cases are excluded from this study.

All patient who enroll to this study was performed total knee replacement by computer assisted navigation system (OrthoPilot ${ }^{\circledR}$ Navigation System, B Braun, Melsungen, Germany), with cruciate retaining - mobile bearing prosthesis design (e. motion ${ }^{\circledR}, \mathrm{B}$ Braun, Melsungen, Germany) and implantation with high viscosity bone cement (Palacos ${ }^{\circledR}$, Zimmer biomet), which working phase between about $1-5$ minutes. The room temperature of Bhumibol Adulyadej hospital's operation room is controlled at about $20-24$ degrees Celsius and the relative humidity is limited about 30 - 60 percent. All cases performed medial parapatellar arthrotomy approach. Navigator arrays were rigidly attached through 4 threaded pins at proximal tibia and distal femur. Bony landmarks, hip center and ankle center was registered. Tibial bone cut was done first, targeted to have frontal plane perpendicular to mechanical axis and posterior tibial slope about 4 degrees. Then soft tissue tension was registered. Implant size, alignment, rotation and position was planned. Aim of the operation is to realigned the mechanical axis closed to 0 degree and balancing rectangular flexion and extension gaps. Femoral bone cut was done as planned. Then trial component was placed. Mechanical axis, range of motion and both medial and lateral gaps in flexion and extension positions were checked and collected. Component implantation was performed at tibial first. Cement mantle was pressurized digitally into cancellous bone and tibial stem. Tibial component was placed and inserted with standard impactor until completely seated into the bone. Mobile bearing polyethylene was placed. Then femoral component was inserted in the same technique. Extruded cement was removed. Knee was completely extended 
to enhance cement pressurization and maintained this position during cement hardening. No any cases performed patellar resurfacing. Axis, range of motion and gaps were then checked and collected to compared between before and after cementation by navigation system.

\section{$\underline{\text { Result }}$}

There are 33 patients was collected in this study. The patient's age is between $52-83$ years old (mean age 63 years old). Most of them are female (29 patients). The operation was performed at left side 17 knees and right side 16 knees. Most of this patient are overweight. The demographic data shows in table 1

Mean gaps, mechanical axis and flexion contracture compare between before and after cementation are show in table 2

\begin{tabular}{|c|c|c|}
\hline & & Mean \\
\hline \multirow[t]{2}{*}{ Medial extension gap } & Trial & $12.48(\mathrm{~mm})$ \\
\hline & $\begin{array}{l}\text { After } \\
\text { cementation }\end{array}$ & $12.76(\mathrm{~mm})$ \\
\hline \multirow[t]{2}{*}{ Lateral extension gap } & Trial & $15.03(\mathrm{~mm})$ \\
\hline & $\begin{array}{l}\text { After } \\
\text { cementation }\end{array}$ & $15.64(\mathrm{~mm})$ \\
\hline \multirow[t]{2}{*}{ Medial flexion gap } & Trial & $8.61(\mathrm{~mm})$ \\
\hline & $\begin{array}{l}\text { After } \\
\text { cementation }\end{array}$ & $8.52(\mathrm{~mm})$ \\
\hline \multirow[t]{2}{*}{ Lateral flexion gap } & Trial & $10.73(\mathrm{~mm})$ \\
\hline & $\begin{array}{l}\text { After } \\
\text { cementation }\end{array}$ & $10.67(\mathrm{~mm})$ \\
\hline \multirow[t]{2}{*}{ Mechanical axis } & Trial & $0.12^{\circ}$ \\
\hline & $\begin{array}{l}\text { After } \\
\text { cementation }\end{array}$ & $0.12^{\circ}$ \\
\hline \multirow[t]{2}{*}{ Flexion contracture } & Trial & $4.36^{\circ}$ \\
\hline & $\begin{array}{l}\text { After } \\
\text { cementation }\end{array}$ & $7.03^{\circ}$ \\
\hline
\end{tabular}


In this study, we found that, lateral extension gap was increase after cementation when compared with before cementation statistical significance $(0.61 \mathrm{~mm}, \mathrm{P}$ value 0.21 ). No statistic significant difference in medial extension, lateral flexion or medial flexion gap. The mechanical axis was also no statistic significant difference when compere before and after cementation. After cementation, knee extension angle was decrease statistic significant difference, flexion contracture from 4.36 degree to 7.03 degree (mean 2.67 degree, $P$ value 0.00).

\begin{tabular}{|l|c|c|}
\hline & Deviation & P value \\
\hline medial extension gap & $0.27(\mathrm{~mm})$ & .213 \\
\hline Lateral extension gap & $0.61(\mathrm{~mm})$ & .021 \\
\hline Medial flexion gap & $-0.09(\mathrm{~mm})$ & .738 \\
\hline Lateral flexion gap & $-0.06(\mathrm{~mm})$ & .810 \\
\hline Mechanical axis & $0.00^{\circ}$ & 1.00 \\
\hline Flexion contracture & $2.67^{\circ}$ & .000 \\
\hline
\end{tabular}

\section{$\underline{\text { Discussion }}$}

This study shown the advantage of navigation system in term of improvement the surgical outcome that, the navigation system can evaluate the mechanical axis and the balancing of gaps immediate intraoperatively. If there are some error in the alignment, surgeon can revise the prosthesis in the same time and no need to get risk to the patient for re-operation.

Chow et al. ${ }^{[20]}$ collected data from the patient who underwent sensor assisted total knee replacement, this data shown $44 \%$ of patient has imbalanced loading pattern after cementation $(\mathrm{P}<0.001) .84 \%$ of imbalanced knee exhibited heavier loads on the medial side, which induced by increasing cement mantle thickness. However, this study does not mention about gap deviation, but we can assume that medial gap could be increasing. Furthermore, they tried to explained this phenomenon that may be caused from unnatural pronation angle of surgeon's left wrist during impaction and caused incomplete medial impaction of femoral component in right handed dominant surgeon. Unlike our study, the lateral extension gap was increase after cementation. This result cannot explain as same as Chow's study, our surgeon was right handedness and we found that side of operation was no statistic significant difference when compere before and after cementation. Possibility caused of increasing in lateral extension gap may be from autoadjustment of normal kinematic of the knee. As we known that, in the native knee, the lateral joint gap is significantly laxer than the medial ${ }^{[21-23]}$. The another caused may be from unaware varus force from surgeon during cement hardening. 
In term of alignment, this study shown no change in the mean of mechanical axis when comparing between before and after cementation $(0$ degrees, $P$ value $1.00)$. But the data from in-depth analysis review that the deviation of mechanical axis after cementation at least 2 degrees is $36.36 \%$ of all patient and deviation at least 3 degrees is $9.1 \%$. Catani et al. ${ }^{[24]}$ reviewed alignment deviations between the bone resections and the subsequent implant placement were $>2$ degrees in the frontal plane of the femur and in the frontal and sagittal planes of the tibia in 4\%,3\%, and $9 \%$ of the patients, respectively. This result similar with our study that positioning of the femoral and tibial components, which mainly involves cementation and impaction of the final components, can introduce a considerable error in alignment, regardless of how accurately the resection planes are made and the benefits obtained by navigation can be lost.

Another study from Shi et al. ${ }^{[25]}$ they found that, no statistically difference in mechanical axis, gap balancing and range of motion when compare between before and after cementation. But femoral component was more internal rotation after cementation $(\mathrm{P}=0.03)$

Moreover, our study reviewed that extension was more restriction after cementation, flexion contracture was increase in 2.67 degrees. This limitation may affect by increase thickness of cement mantle in distal femoral bone.

However, there is a small amount of increase lateral extension gap, alignment and flexion contracture. This deviation needs further investigation on the impact of clinical correlation. It may be useful to control and recheck gap and alignment with navigation system during cementation. But care must take if surgeon try to maintain the component in the correct position with the navigation display monitor, because motion during adjustment may interfere cement hardening and may caused poor cement technique.

The limitation of this study is no clinical outcome correlation and alignment was collected in coronal plane only.

\section{$\underline{\text { Conclusion }}$}

Cementation is able to influence gap and alignment. It may be useful to control and recheck gap and alignment with navigation system during cementation. Clinical correlation needs further investigation.

\section{$\underline{\text { Reference }}$}

1. Zenat Khired. The influence of improvement in pain and function after total knee replacement in patient satisfaction. J Clin Res Pharm 2018 Volume 1 Issue 1 
Gap Deviation after Cementation in Computer Assisted ... C. Leelasestaporn and T. Tarnpichprasert

2. Gary Hooper, Alex J-J Lee, Alastair Rothwell, Chris Frampton. Current trends and projections in the utilisation rates of hip and knee replacement in New Zealand from 2001 to 2026. NZMJ 29 August 2014, Vol 127 No 1401

3. Lotke PA, Ecker ML. Influence of positioning of prosthesis in total knee replacement. J Bone Joint Surg Am. 1977 Jan; 59(1):77 - 9.

4. Watanabe T, Muneta T, Sekiya I, et al. Intraoperative joint gaps and mediolateral balance affect postoperative knee kinematics in posteriorstabilized total knee arthroplasty. Knee 2015; 22:527 - 34.

5. KY Chiu, TP Ng, WM Tang, WP Yau. Review article: Knee flexion after total knee arthroplasty. Journal of Orthopaedic Surgery 2002:10(2): 194 - 202

6. Wasielewski RC, Galante JO, Leighty RM, Natarajan RN, Rosenberg AG. Wear patterns on retrieved polyethylene tibial inserts and their relationship to technical considerations during total knee arthroplasty. Clin Orthop Relat Res.1994 Feb;(299):31-43.

7. Bargren JH, Blaha JD, Freeman MA. Alignment in total knee arthroplasty. Correlated biomechanical and clinical observations. Clin Orthop Relat Res. 1983 Mar;(173):178-83.

8. Ritter MA, Faris PM, Keating EM, Meding JB. Postoperative alignment of total knee replacement. Its effect on survival. Clin Orthop Relat Res. 1994 Feb;(299):153-6.

9. Sharkey PF, Hozack WJ, Rothman RH, et al. Insall Award paper. Why are total knee arthroplasties failing today? Clin Orthop Relat Res 2002;(404):713.

10. Berend ME, Ritter MA, Meding JB, Faris PM, Keating EM, Redelman R, et al. Tibial component failure mechanisms in total knee arthroplasty. Clin Orthop Relat Res. 2004 Nov;(428):26-34.

11. Ahmed Jawhar, Karolin Hutter, Hanns-Peter Scharf. Outcome in total knee arthroplasty with a medial-lateral balanced versus unbalanced gap. Journal of Orthopaedic Surgery 2016;24(3):298-301.

12. Dorr LD, Boiardo RA. Technical considerations in total knee arthroplasty. Clin Orthop Relat Res 1986; 205:5-11.

13. Sparmann M, Wolke B, Czupalla H, Banzer D, Zink A. Positioning of total knee arthroplasty with and without navigation support. A prospective, randomized study. J Bone Joint Surg Br 2003; 85:830-5.

14. Laskin RS, Beksac B. Computer-assisted navigation in TKA: where we are and where we are going. Clin Orthop Relat Res 2006; 452: 127-31 
Gap Deviation after Cementation in Computer Assisted ... C. Leelasestaporn and T. Tarnpichprasert

15. Lutzner J, Krummenauer F, Wolf C, Gunther KP, Kirschner S. Computerassisted and conventional total knee replacement: a comparative, prospective, randomized study with radiological and CT evaluation. J Bone Joint Surg Br 2008; 90:1039-44.

16. Bäthis H, Perlick L, Tingart M, Lüring C, Zurakowski D, Grifka J. Alignment in total knee arthroplasty. A comparison of computer-assisted surgery with the conventional technique. J Bone Joint Surg Br. 2004 Jul;)865:(682-7

17. Hee-Nee Pang, Seng-Jin Yeo, Hwei-Chi Chong, Pak-Lin Chin, Johnny Ong, Ngai-Nung Lo. Computer-assisted gap balancing technique improves outcome in total knee arthroplasty, compared with conventional measured resection technique. Kneea Surgery, Sports Traumatology, Arthroscopy. 2011 Sept; 19(9), 1496-1503

18. Abhijit Ranjan Guha, Ujjwal Kanti Debnath, and Niall McKenzie Graham. Radiolucent lines below the tibial component of a total knee replacement (TKR) - a comparison between single-and two-stage cementation techniques. Int Orthop. 2008 Aug; 32(4): 453-457.

19. Douglas A Dennis, Rick Kowalski. Cement technique in total knee arthroplasty. DePuy Synthes.DSUS/JRC/1114/0581 06/15.

20. Jimmy Chow, Kevin Wang, Leah Elson, Christopher Anderson, Martin Roche. Effects of Cementing on Ligament Balance During Total Knee Arthroplasty. Orthopedics. 2017; 40(3):e455-e459.

21. Tokuhara Y., Kadoya Y., Nakagawa S., Kobayashi A., Takaoka K. The flexion gap in normal knees. An MRI study. J. Bone Joint Surg. Br. 2004;86(8):1133-1136. doi: 10.1302/0301-620X.86B8.15246.

22. Philippe Van Overschelde, Vera Pinskerova, Peter P. Koch, Christophe Fornasieri, Sandro Fucentese. Redefining Knee Balance in a Medially Stabilized Prosthesis: An In-Vitro Study. Open Orthop J. 2017; 11: 11651172.

23. Johal P, Williams A, Wragg P, Hunt D, Gedroyc W. Tibio-femoral movement in the living knee. A study of weight bearing and non-weight bearing knee kinematics using 'interventional' MRI. J Biomech. 2005 Feb;38(2):269-76.

24. Fabio Catani, Nicola Biasca, Andrea Ensini, Alberto Leardini, Luca Bianchi, Vitantonio Digennaro, et al. Alignment Deviation Between Bone Resection 
Gap Deviation after Cementation in Computer Assisted ... C. Leelasestaporn and T. Tarnpichprasert

and Final Implant Positioning in Computer-Navigated Total Knee

Arthroplasty. J Bone Joint Surg Am. 2008; 90:765-71

25. Dongquan Shi, Xingquan Xu, Anyun Guo, Jin Dai, Zhihong Xu, Dongyang Chen, et al. Bone Cement Solidifiliation Influence the Limb Alignment and Gap Balance during TKA. BioMed Research International 2015, Article ID 109402 